\title{
Slang in American and British Hip-Hop/Rap Song Lyrics
}

\author{
Tessa Zelyana Hidayat*, Rio Rini Diah Moehkardi \\ Universitas Gadjah Mada, Indonesia \\ *Email: sellazelyana@gmail.com
}

\begin{abstract}
A B S T R A C T
This research examines semantic changes and also the associative patterns of slang, focusing primarily on common topics, i.e., people and drugs. The data were slang terms taken from the lyrics of hip-hop/rap songs sung by four singers, two from the U.S.A and two from the U.K. A total of 105 slang terms were found, 45 of which belong to the people category and 16 to the drugs category in the American hip-hop/rap song lyrics, and in the British hip-hop/rap song lyrics, 26 of which belong to the people category and 18 to the drugs category. Bitch and nigga were found to be the most frequently used slang terms in the people category. In terms of semantic changes, broadening, amelioration, and narrowing were found, and in terms of associative patterns, effect, appearance, way of consuming, constituent, and container associative patterns were found. In addition, a new associative pattern was found, i.e., place of origin.
\end{abstract}

Keywords: associative patterns, people and drugs slang, semantic change, slang.

\section{INTRODUCTION}

“This party is just unreal!" Imagine a person saying this sentence in the biggest New Year's Eve party in his/her town, with the largest crowd, the loudest music, and the most spectacular fireworks show ever. This sentence, however, does not mean that the party he/she is attending is not real or imaginary. It means that the party is really awesome or too good to be true. In that context, the word unreal does not hold the formal unreal meaning as we all have learned. The word has undergone changes in its meaning. It is used as a slang term.

It is undeniably difficult to find the most 'accurate' origin of slang in general. Different countries or any different areas of a language in the world have different history in terms of when and why it existed. However, Andersson and Trudgill (1990) argue that slang was originally "used by British criminals to refer to their own special language." During the $16^{\text {th }}$ century, British criminals such as thieves, prostitutes, pickpockets, etc, used a special kind of speech called Cant to mislead people outside their group. Then, the usage of Cant began to slowly develop. Larger groups started to talk Cant in their daily life. It was even used for entertainment purposes, such as in literature. Rogue literature, a literary genre that tells stories from the world of thieves and other criminals, is known with one of its common features, which is Cant. During the Elizabethan period in England, Cant could often be found in pamphlets and Elizabethan theatre.

As time passed by, civilizations change and so do their entertainment sources. Traditional theatrical shows and plays were getting less audience. Fast forward to $21^{\text {st }}$ century, people seek entertainment through technology that they can easily get almost anywhere, and anytime. As traditional plays develop into movies, traditional music develop into modern ones with many genres, and so does Cant develop into slang with broader meanings and speakers. If Cant used to be mostly spoken by criminals, nowadays slang is mostly spoken by ghettos. A commonly used definition of a ghetto is a community distinguished by a homogeneous race or ethnicity. 
Usually, they are separated from other major societies because of their social, legal, or economic pressure. Although the words and their speakers change, the pattern of slang usage and purpose stays the same-to be secretive. A clearer and more complete definition of slang according to Eble (1996, p. 11) is "an ever-changing set of colloquial words and phrases that speakers use to establish or reinforce social identity or cohesiveness within a group or with a trend or fashion in society at large."

People create slang words because they need their own language. Using a language that is particular to their tribe and time is part of developing self-esteem, confidence and, crucially, a sense of identity and belonging. That is why sometimes a certain group of people has different slang from another.

Slang is no longer being created by people in their small groups and stay that way, especially in a world like today where everything moves fast. It shows up a lot in popular culture such as books, movies, television shows, the Internet, and music. In music, many artists use slang in their song lyrics to express their own identities and characteristics. Almost all music genres contain some slang terms in their song lyrics, but not as many as in hip-hop/rap song lyrics. Many of the slang which become hip and are reused by people everyday in their conversations are in hip-hop/rap music. That is why the present research focuses on hip-hop/rap genre. Hip-hop and rap are two very similar and interconnecting genres, because the elements associated with the sound of the music such as beat, rhyme and style are mostly the same. However, rap music mostly all about "telling it like it is", while hip-hop strives to push its listeners to look forward to a better tomorrow by telling them more positive messages. But now, many artists have those elements together in their songs, so the differences between each genre blur out.

As the origin of hip-hop itself is from South Bronx, New York City, America in 1970s, therefore most well known hip-hop/rap artists in the decade were from America too. Even if there are other world widely famous artists from outside America, they follow the same rules and patterns of slang used by the U.S. hip-hop artists. Hip-hop became known world wide in the late 1980s along with the rise of the new media platforms and technology such as the Internet. It grows so fast and fans would primarily consume it through social networking sites (SNS) beginning with MySpace, YouTube, Worldstarhiphop, and Spotify. However, the present research focuses on American and British hip-hop/rap songs for several reasons. First, America is the birth place of hip-hop. Second, although English is spoken in many countries around the globe, British and American English is the reference for English as spoken, written, and taught in the rest of the world. Third, most widely known hip-hop artists with great achievements in their career are mostly from the U.S. and U.K.

Hip-hop has distinctive slang. Due to hiphop's extraordinary commercial success in the late nineties and early $21^{\text {st }}$ century, many of the slang words used in its song lyrics have been assimilated into different dialects across America and the world and even to non-hip-hop fans. There are many slang words from Hip-Hop/Rap song lyrics that become trends and sensations in pop culture, such as cool, dude, and dope. Like many other trends that revolve around this world, some go big and stay hyped for a moment and then gone, some other still hyped for a long time. Some, which have transcended time and remained in use until now, is because it is easy to use and applied in people's actual daily life conversations. Though, some lasting slang might still exist, most of them shift meaning, following the situation and surrounding of the speakers at certain time. Hence, the meaning and usage of slang really depend on and coordinate with the period and place in which the users live, which in this case is the U.S. and the U.K. And since the slang words revolve around those two countries and the world, it is assumed that there are some differences and similarities between the slang words used in the U.S. and the U.K. and how they change their meaning.

\section{THEORETICAL FRAMEWORK}

\section{Slang}


As mentioned earlier, according to Eble (1996, p. 11), slang is "an ever-changing set of colloquial words and phrases that speakers use to establish or reinforce social identity or cohesiveness within a group or with a trend or fashion in society at large."

According to Akmajian et al. (2001, p. 301), slang has some salient features. First, slang is part of casual informal styles of language use. Second, slang is like fashion in clothing and popular music, which changes quite rapidly. Third, specific areas of slang are often associated with a particular social group, and hence one can speak of teenage slang, underworld (criminal) slang, the slang of the drug culture and so on.

\section{Semantic Change and Associative Patterns}

Hollmann (2009) says that a classification of changes in meaning when the meaning becomes broader is called broadening. Narrowing is the opposite; the meaning becomes specified. Amelioration is a type of semantic change where the word meaning experiences changes into a more positive meaning. Hollman's theory of semantic change is used because it observes how words such as bitch and nigger evolve their meaning and change their referents/objects. However, for drugs slang, Mottiello's (2008) associative pattern is used.

In drugs category, one object has various slang words, yet one meaning. This happens because slang words for drugs (marijuana, MDMA, heroin, cocaine, and ketamine) need to be renamed and continuously changed, so it would be harder for 'the outsiders' or 'the non-user' to know about the drugs. Matiello (2008) classifies associative relations in semantic change into effect, appearance, way of consuming, constituent, and container patterns.

\section{METHODS}

The data of this research are slang words used in the lyrics of hip-hop/rap songs sung by 4 selected artists, two from the United States of America, i.e., Eminem and Wiz Khalifa, and two from the United Kingdom, i.e., Dizzee Rascal and Skepta. Only one of the most recent albums of each artist was chosen: Marshal Mathers II by Eminem (2013), Khalifa by Wiz Khalifa (2016),
The Fifth by Dizzee Rascal (2013), and Konnichiwa by Skepta (2016) (See Appendix I for a complete list of songs in each album).

The four artists above were selected because they are the most popular hip-hop/rap artists in each country. They have been in their career in hip-hop for years and been receiving awards and other achievements from many industries. Their songs often set in top position on music charts like Billboards, BBC, MTV, etc. They also use some slang words that have actually already existed yet rarely used in daily conversation. However, because they have so many listeners around the world, the slang words easily spread out and people use them. In other words, they have been indirectly contributing to preserving slang from time to time.

Hip-hop/Rap songs mostly tell stories about the artists' real life and their surroundings. And mostly, the artists lived a harsh life, bad childhood, broken home family, being bullied, etc. That is the reason why most of the songs contain a series of bad words telling bad stories or topics. To narrow down the scope, the present research focuses on slang words related to the two most popular topics in Hip-Hop/Rap songs, which are people and drugs.

\section{RESULTS AND DISCUSSION}

\section{Semantic Changes on People terms}

\section{Broadening}

Broadening of 'bitch' and 'nigga' is found in both American and British Hip-Hop/Rap Songs.

\section{Bitch}

According to Dalzell and Victor (2008), the word bitch has kept progressing since the first time it was acknowledged. In the UK, in 1400, bitch basically meant "a despicable woman". Then in 1713, bitch changed into "a woman". Although it is considered "the most offensive appellation that can be given to an English woman" (p. 58), it is used in this sense with no derogatory intent; it is dismissive or patronizing, based on gender rather than the unpleasant and lewd characteristics of earlier and concurrent usages. While in the U.S., other than "woman", bitch had more various meanings. In 1923, it meant "the 
person taking the passive role in a male homosexual relationship; a feminine or weak man." Then in 1943, it expanded into "a remarkable person or thing." Although bitch word keeps changing from time to time, the root of its origin meaning, which is basically "despicable woman" is still more dominant than the other meanings.

\section{Bitch meaning competitors at rap battles}

In the song Rhyme or Reason, Eminem (US) says:

(1) "But lyrically, I never hear a peep, not even a whisper /Rappers better stay clear of me, bitch."

Eminem is saying that when he raps, he screams and curses so fast and loud that his competitors in rap battles are not secure enough to speak their mind around him and risk getting dissed, so they would rather just go silent.

Bitch here is addressed to the competitors at rap battles. It has expanded from women into people with both sexes; men and women.

\section{Bitch meaning a despicable person}

In the same song Rhyme or Reason, Eminem (US) says:

(2) "So, bitch, shoot me a look, it better be a blank stare/Or get shanked in the pancreas."

Eminem is threatening the person he despises to not stare at him because he hates it so much.

Bitch here has expanded its meaning from a despicable woman into a despicable person regardless of the gender; they could be a man or woman or both.

\section{Bitch meaning enemies}

In the song Legacy, Eminem (US) says:

(3) "Now you shut up, bitch, I am talking /Thought I was full of horseshit, /and now you fucking worship the ground on which I am walking."

Eminem is singing this line to the enemies he has since he was a little kid.
Bitch here is addressed to his enemies. This word has expanded from a derogatory woman to people he hates; regardless of the gender, they could be men or women.

\section{Bitch meaning a retarded woman}

In the song Asshole, Eminem (US) says:

(4) 'You crackin' a joke, it's laughable. /Cause me and love's like a bad combination. /I keep them feelings locked in a vault. /So it's safe to say I'm uncrackable. /My heart is truly guarded, full body armor. / $\underline{\text { Bitch }}$, you just need a helmet. /'Cause if you think you're special, you're retarded."

Eminem does not care about what people are saying; it is like he is wearing a full body armor. Women are only special in the sense that they have some special needs, and if they have elevated opinions of themselves, it further emphasizes that fact. Also, people with special needs sometimes wear helmets to prevent harm to themselves.

Bitch here is addressed to the woman he despises. He is saying that if this woman thinks she is special then she is so stupid and retarded. Therefore, bitch here has expanded from a despicable woman to a despicable and retarded woman.

\section{Bitch meaning a coward}

In the song Brainless, Eminem (US) says:

"Cause I feel like a little bitch, this predicament's despicable. /I'm sick of getting pushed, it's ridiculous."

Eminem refers to his youth when he was constantly bullied by people around him. Those memories stick to him until now. The feeling of hopelessness was real, and sometimes he still feels it until now.

Bitch here means a weak and helpless person. It changes from the original meaning "a despicable woman" into "a weak and helpless person", who can be man or woman. This semantic change that happens to bitch here is called broadening.

Bitch meaning despised people 
Meanwhile from British artist, the semantic change broadening is only found in one feature only which is for despised people.

In the song $H$-Town, Dizzee Rascal (UK) says:

(6) "You better back up, bitch, and show respect, /before you get your ass checked."

At the club, Dizzee Rascal is telling that people should be having fun instead of looking for trouble with other people. If you disturb anyone, or Dizzee Rascal himself, you'd better not and show respect before he and his friends beat you up.

Bitch here means people in general that Dizzee Rascal despises. It can refer to men or women. Therefore, the word bitch experiences semantic change called broadening.

\section{Nigga}

According Dalzell and Victor (2008), the word 'nigga' was actually first acknowledged in the U.K. in 1574. The first meaning was "A black person. When it is used by white speakers, it is highly offensive; but not when used by black speakers, especially the young, with increasing frequency" (p. 457). Then, in 1980s, nigga began to be widely used in the U.S. with the meaning of "A black person. A deliberate misspelling, reinvent-ing NIGGER for exclusive black use; widely used in gangsta rap" (p. 457).

\section{Nigga meaning people in general}

In the song BTS, Wiz Khalifa (US) says:

(7) "Niggàs still hating, critics still waiting."

Through that particular line, Wiz Khalifa is saying that people always have the reasons to hate him no matter what he does.

However, in the song It Ain't Safe, Skepta (UK) says:

\section{(8) "These niggas follow fashion, don't look} comfy in their clothes."

What Skepta is trying to get at in this line is that nowadays people only look into the trends, not what they like and what is comfortable for them. The point is what all people actually care about is the name, and not what they are wearing, although it is ridiculous and uncomfortable.

The word nigga from both songs means people in general. Nigga experiences semantic change called broadening, because the word changes from the original nigga as a black person into people in general, which can include white people as well.

\section{Narrowing}

If broadening is a type of semantic change in which the meaning becomes broader, narrowing is the opposite; the meaning becomes more specified. This type of semantic change was found to happen to the word nigga, but not to bitch.

\section{Nigga}

\section{Nigga meaning a man}

In the song “ $B T S$, ” Wiz Khalifa (US) says:

"My momma ain't raise a fool nigga."

Wiz Khalifa is saying that his mother raised him to be a smart and great, not fool man.

Nigga here means an individual, but because Wiz Khalifa who sings the line, it means a man. Although the original meaning of nigga is a black person and Wiz Khalifa himself is also black, nigga here is specifically means a person with one gender: man. Therefore, the word nigga here experiences semantic change called narrowing.

\section{Amelioration}

Amelioration is a type of semantic change where the word meaning experiences changes into a more positive meaning.

\section{Bitch}

\section{Bitch meaning neutral women in general}

In the song BTS, Eminem (US) says:

(10) "I hate all bitches the same, baby come on /Cause a woman broke my he-art / I say heart cause she ripped it in two pa-arts."

Eminem is saying that basically women around him are all the same; they will end up breaking his heart.

Bitch here means women in general. It has no longer derogatory meaning even though in that 
line the women do something bad like breaking Eminem's heart. The word bitch here experience semantic change called amelioration. The word changes from the original bitch as a despicable woman to bitch as women in general. However, bitch here also experience broadening, because the word changes from the original bitch as a calling for one woman to women in general.

\section{Bitch meaning a neutral address term}

In the song So Much Better, Eminem (US) says:

(11) "So all that love shit is null and void, / $\underline{\text { bitch, }}$ I'm a droid."

Eminem is telling his listeners that love is nothing and does not give anything in return. He does not trust women anymore and has no feelings towards them like a robot.

In addition, from British artist, in the song Spend Some Money, Dizzee Rascal (UK) says:

(12) "Bitch, this is Audemars, not a Hublot."

Dizzee Rascal sings this line to compare him to young posers who wear brands for the sake of looking like rich people, without really knowing the brand itself. He wants to show them that he is really rich and knows the real luxurious brands. Both Audemars and Hublot are expensive watches, but Audemars is like the Big Ben of the watch world.

Bitch is here used to address people in general. It has no derogatory meaning. It is the same as guys, dude, or other addressing terms for people in general. Hence, the word bitch here experiences amelioration.

\section{Bitch meaning a girlfriend}

In the song So Much Better, Eminem (US) says:
(13) "I'm just playing, bitch, you know I love you."

Throughout the whole song, Eminem tells the listeners about his girlfriend's flaws and bad attitudes. He also mentions that he does not care too much about her. However, in the end of the song, he says he is only kidding. All the hate talking done by Eminem might be facts, but in the end, Eminem actually loves the girl.
Bitch here means an adored and beloved woman. It has no derogatory meaning at all. It is the same as babe, darling, or other address terms for the beloved ones. Hence, the word bitch here experiences semantic change called amelioration.

\section{Nigga}

\section{Nigga meaning friends}

In the song Celebrate, Wiz Khalifa (US) says:

(14) "Y'all niggas ask prices, my niggas buy it all."

When people usually ask prices first before buying weeds or other things, Wiz Khalifa and his friends never do it. They always buy things when they want to, not caring about prices at all.

Furthermore, from British artist, in the song Corn on The Curb, Skepta (UK) says:

(15) "Corn on the curb if a man diss me, my niggas got the biscuits in T."

"Corn on the Curb" is a phrase referring to how people's teeth end up all over the pavement from either fighting or a curb stomping. T refers to Tottenham which is an area in North London that Skepta and many of his close associates are from. This means that if someone tries to diss Skepta, one of his associates has a biscuit (a slang word meaning a gun). There is also a wordplay of putting biscuits in a cup of "tea".

Nigga in both songs here loses its derogatory meaning, and changes into friends, crew or team, which is more positive. That is why this word experiences amelioration.

\section{Nigga meaning a neutral address term}

In the song City View, Wiz Khalifa (US) says:

(16) "This shit ain't as easy as it looks, nigga."

Wiz Khalifa is telling people that sometimes things are not as easy as they look.

Nigga here means an address term referring to people in general. It has no derogatory meaning. It is the same as guys, dude, or other address terms for people in general. Hence, the word nigga here experiences semantic change called amelioration. 


\section{Semantic Change in Drugs Slang}

The approach adopted for the analysis of slang that belongs to the drugs category is different from that belonging to the people category because the way the drugs slang terms are used is different from those belonging to the people category. If one slang word in the people category can have various meanings, in the drugs category, one object has various slang words. This happens because slang for drugs need to be various and keep changing, so it would be harder for 'the outsiders' or 'the non-user' to know about the drugs. Each small area has different slang, let alone big countries like the U.S. and the U.K. However, in this research, only five types of drugs were found that are used in American and British Hip-Hop/Rap Songs, which are marijuana, MDMA, heroin, cocaine, and ketamine. The analysis of the slang terms here is based on Matiello's (2008, pp. 169-193) classification of associative patterns in semantic change into five patterns: appearance, effect, constituent, container and way of consuming. In addition to these five patterns, a new pattern was found, i.e., place of origin pattern (See Appendix II for the list of slang words in the drugs category and their associative patterns). Out of the 28 slang terms found in the song lyrics, only three, i.e., weed, pack and purple, were found in both the American and British song lyrics. This indicates that each country seems to have its own slang for drugs. Discussed in detail below is each slang category of drugs and its associative patterns.

\section{Marijuana}

This is the common term for the following slang words.

\section{Weed}

Both American and British Hip-Hop/Rap Artists use weed a lot in their songs. Wiz Khalifa, uses weed $28.5 \%$ out of all drugs slang in his songs. While Dizzee Rascal uses 14.2\%, and Skepta uses $15.3 \%$. All weed in their songs mean the same, which is marijuana or cannabis. The form is mostly dried and shredded. The way of consuming is also the same, which is being smoked like a cigarette. It was believed to have originated in the mountainous regions northwest of the Himalayas, which is a kind of rural area for plants to grow. Therefore, because of the peculiar form, imperfect flowers, and rural growing place, Cannabis is called weed and its associative pattern is the appearance pattern.

Here is one example of weed in American Hip-Hop/Rap song lyrics. In the song Celebrate, Wiz Khalifa (US) says:

$$
\text { "Smoke weed everyday." }
$$

\section{Pack}

Pack is also slang for marijuana, but in a package. Hence, the associative pattern of pack is the container pattern. Usually, one pack is about 5 pounds of marijuana leaves or the whole plant, which are sometimes already dried but not shredded yet. The way of consuming in the end is similar to weed, which is being smoked. Here is one example of pack in British Hip-Hop/Rap song lyrics:

In the song It Ain't Safe, Skepta (UK) says:

"Packs, I sold, had them buzzing on the road."

\section{Bud}

In botany, a bud is a compact knob-like growth on a plant, which develops into a leaf, flower, or shoot. In 1978, it changed into the flower of the marijuana plant, hence marijuana. Hence, the associative pattern of bud is the constituent pattern. The common way of using it is being smoked.

In the song Detox, Skepta (UK) says:

(19) "14 when I started smoking bud./Eversince way back then..."

\section{$M D M A$}

Like marijuana, MDMA is also a constant player in Hip-Hop/Rap music. However, according to National Institute on Drug Abuse, MDMA, or 3,4-methylenedioxy-methamphetamine, is a synthetic drug that alters mood and perception (awareness of surrounding objects and conditions). MDMA itself was initially popular in the nightclub scene and at all-night dance parties, 
but now hip-hop rappers also use it severely, both in real life and in song lyrics.

Pill

As commonly known, a pill is a small round mass of solid medicine for swallowing whole. It is basically drugs already. However, it is also being misused into recreational drugs. Slang is present here and changes the literal meaning from a tablet of medicine in general into a tablet of MDMA, or best known as ecstasy. The common way of using pill is like using any other pill, which is being swallowed or being crushed into powder and then being snorted. It experiences narrowing. The associative pattern of pill is the appearance pattern. Here is an example of pill usage, mentioned by Eminem through his song Rap God:

In the song Rap God, Eminem (US) says:

(20) "Ungh, school flunky, pill junkie. /But look at the accolades these skills bring me."

\section{Saucer}

Saucer, lexically, is a shallow dish, typically having a circular indentation in the center, on which a cup is placed. In slang world, saucer is a tablet of MDMA, the recreational drug best known as ecstasy. It is called saucer because the common way of using it is to crush it to powder and then put it on top of the real saucer, which is the shallow dish, and then snort the powder. Hence, the associative pattern of saucer is the way of consuming pattern. This slang is more popular in UK than US. Here is an example of saucer usage, mentioned by Dizzee Rascal through his song Goin' Crazy.

In the song Goin' Crazy, Dizzee Rascal (UK) says:

(21) "Lamb to the slaughter, life's getting shorter. /Tryin'a get high off a quarter. /I'm fly in a saucer, /my life is a corker."

\section{Heroin}

Heroin is a drug made from morphine, a natural substance taken from the seedpod of the Asian opium poppy plant. Heroin can be a white or brown powder, or a black sticky substance known as black tar heroin.

\section{Sack}

Sack has a similar case to stash. Lexically, sack has meaning of a large bag made of a strong material such as hessian, thick paper, or plastic, used for storing and carrying goods. According to Dalzell and Victor (2008), sack means a bag of heroin. Hence, the associative pattern of sack is the container pattern. The word was first known used in 1998. It experiences narrowing.

In the song So Far..., Eminem (US) says:

(22) 'Don't know what I'd be doin' rap for.

Probably for a giant sack."

\section{Cocaine}

Cocaine comes from the leaves of a SouthAmerican plant called "coca". That is where the name of the drug comes from. The coca leaves then being processed into many kinds of appearance, such as salt, white powder, and also tea.

\section{Cloud}

The literal meaning of cloud is a visible mass of condensed watery vapor floating in the atmosphere, typically high above the general level of the ground. According to Dalzell and Victor (2008), cloud means cocaine. The slang cloud is derived from the thick white smoke produced like cloud in the sky when smoked. Hence, the associative pattern of cloud is the appearance pattern.

In the song Love Game, Eminem (US) says:

(23) 'Something's burning, I can't figure out what. It's either lust or a cloud of dust. Judgment is clouded; must. Just be the powder from the power of love."

\section{Crack}

Crack is cocaine that has chemicals added to it that end up turning the powdered cocaine into a more solid material that is then broken into little pieces like little rocks. The common way of using this kind of drug is to 'crack' it first, and then snort or smoke it. Hence, the associative pattern of crack is the way of consuming pattern. 
In the song It Ain't Safe, Skepta (UK) says:

(24) "Packs (and cracks), I sold, had them buzzing on the road. /Crack_residue in the buttons on my phone."

\section{Ketamine}

Ketamine hydrochloride or Ketamine type has one slang word, which is Purple. It is a quickacting anesthetic that is legally used in both humans (as a sedative for minor surgery) and animals (as a tranquilizer). At high doses, it causes intoxication and hallucinations similar to LSD. Often, it is injected, but it can also be dried into powder and then snorted, or mixed with either tobacco or marijuana to be smoked. The package is various; sometimes it is in mini bottles or capsules, which mostly the color is purple. Hence, the name is also purple and its associative pattern is the appearance pattern. Here are several examples of purple in American and British Hip-Hop/Rap songs lyrics:

In the song Numbers, Skepta (UK) says:

(25) "Got the X, got the purple, got the green." In the song Zoney, Wiz Khalifa (US) says:

(26) "Too much purple for me."

\section{CONCLUSION}

From the discussion above, it can be concluded that a total of 105 slang words were found in the four albums under investigation. In Eminem's Marshall Mathers 2 (2013) album, a total of 41 slang words were found, 36 of which belong to the people category and five words to the drugs category. In Wiz Khalifa's Khalifa album (2016), a total of 20 slang words were found, nine of which belong to the people category and 11 to the drugs category. In Dizzee Rascal's The Fifth album (2013), a total of 20 slang words were found, 13 of which belong to the people category and seven to the drugs category. And in Skepta's Konnichiwa album (2016), a total of 24 slang words were found, 13 of which belong to the people category and 11 to the drugs category.

The findings also indicate that several semantic changes were found in American and British Hip-Hop/Rap songs, especially in the people category. In the American Hip-Hop/Rap songs, for the word bitch, three occurrences were found to have undergone amelioration and four undergoing broadening, while for the word nigga, one occurrence was found to have undergone broadening, one narrowing, and two amelioration. In British Hip-Hop/Rap songs, for the word bitch, two occurrences were found to have undergone amelioration and one broadening. And for the word nigga, one occurrence was found to have undergone broadening and one amelioration.

In American and British Hip-Hop/Rap drugs slang, six associative patterns of semantic change were found. In addition to the five patterns proposed by Mattiello (), i.e., appearance, effect, constituent, container and way of consuming patterns, one new associative pattern, called place of origin pattern, was found. This pattern is based on the place where the object comes from.

\section{REFERENCES}

Andersson, G. and P. Trudgill. (1990). Bad language. Hoboken, N.J.: Blackwell.

Dalzell, T. and Victor, T. (eds.). (2008). The Concise New Partridge Dictionary of Slang and Unconventional English. London: Routledge.

Eble, C. (1996). Slang and sociability: in-group language among college students. Chapel Hill: The University of North Carolina Press.

Eminem. (2013). The Marshall Mathers LP2. Genius Media Group. Inc. https://genius.com/albums/ Eminem/The-marshall-mathers-lp2. Accessed 26 August 2016.

Hollmann, Willem B. (2009). Semantic change. In J. Culpeper, F. Katamba, P. Kerswill, and T. McEnery (Eds.), English language: description, variation and context, pp. 301313. Basingstoke: Palgrave.

Khalifa, Wiz. (2016). Khalifa. Genius Media Group. Inc. https://genius.com/albums/Wizkhalifa/Khalifa. Accessed 26 August 2016. 
Mattiello, Elisa. An Introduction to English Slang. A Description of its Morphology, Semantics and Sociology. Polimetrica. 2008.

Rascal, Dizzee. (2013). The Fifth. Genius Media Group. Inc. https://genius.com/albums/ Dizzee-rascal/The-fifth. Accessed 26 August 2016.

Skepta. (2016). Konnichiwa. Genius Media Group. Inc. https://genius.com/albums/Skepta/ Konnichiwa. Accessed 26 August 2016.

\section{APPENDICES}

\section{Appendix I}

List of songs in each album.

\section{Dizzee Rascal: The Fifth (2013)}

1. Superman

2. I Don't Need or Reason

3. We Don't Play Around

4. Good

5. Spend Some Money

6. Arse Like That

7. Something Really Bad

8. Goin' Crazy

9. Bang Bang

10. Love This Town

11. H-Town

12. Heart of a Warrior

13. Life Keeps Moving On

14. Here 2 China

15. Bassline Junkie

16. Watch Your Back

Eminem: Marshall Mathers 2(2013)

1. Bad Guy

2. Parking Lot (Skit)

3. Rhyme or Reason

4. So Much Better
5. Survival

6. Legacy

7. Asshole

8. Berzerk

9. Rap God

10. Brainless

11. Stronger Than I Was

12. The Monster

13. So Far...

14. Love Game

15. Headlights

16. Evil Twin

\section{Skepta: Konnichiwa (2016)}

1. Konnichiwa

2. Lyrics

3. Corn on the Curb

4. Crime Riddim

5. It Ain "t Safe

6. Ladies Hit Squad

7. Numbers

8. Man

9. Shutdown

10. That"s Not Me

11. Detox

12. Text Me Back

Wiz Khalifa: Konnichiwa (2016)

1. BTS

2. Celebrate

3. Elevated

4. City View

5. Cowboy

6. Bake Sale

7. Call Waiting

8. Make a Play

9. Most of Us

10. Zoney

11. Lit

12. No Permission

13. iSay 


\section{Appendix II}

List of drugs slang words and their associative patterns.

\begin{tabular}{|c|c|c|c|c|c|c|c|c|}
\hline \multirow{2}{*}{ Type } & \multirow{2}{*}{ Country } & \multirow{2}{*}{ Slang } & \multicolumn{6}{|c|}{ Associative Patterns } \\
\hline & & & App. & Eff. & Cons. & Cont. & Way & Place \\
\hline \multirow{18}{*}{ Marijuana } & \multirow{8}{*}{ US } & kush & & & & & & $\sqrt{ }$ \\
\hline & & KK & & & & & & $\sqrt{ }$ \\
\hline & & smoke & & & & & $\sqrt{ }$ & \\
\hline & & joint & $\sqrt{ }$ & & & & & \\
\hline & & J & $\sqrt{ }$ & & & & & \\
\hline & & bomb & & $\sqrt{ }$ & & & & \\
\hline & & dank & $\sqrt{ }$ & & & & & \\
\hline & & dope & & $\sqrt{ }$ & & & & \\
\hline & \multirow{8}{*}{ UK } & stash & & & & $\sqrt{ }$ & & \\
\hline & & spliff & & & $\sqrt{ }$ & & & \\
\hline & & swisher & & & & $\sqrt{ }$ & & \\
\hline & & green & $\sqrt{ }$ & & & & & \\
\hline & & indo & & & & & & $\sqrt{ }$ \\
\hline & & loud & $\sqrt{ }$ & & & & & \\
\hline & & bud & & & $\sqrt{ }$ & & & \\
\hline & & zoot & $\sqrt{ }$ & & & & & \\
\hline & US and & weed & $\sqrt{ }$ & & & & & \\
\hline & UK & pack & & & & $\sqrt{ }$ & & \\
\hline \multirow{4}{*}{$\begin{array}{l}\text { MDMA or } \\
\text { Ecstasy }\end{array}$} & US & pill & $\sqrt{ }$ & & & & & \\
\hline & & tango & & $\sqrt{ }$ & & & & \\
\hline & UK & saucer & & & & & $\sqrt{ }$ & \\
\hline & & $\mathrm{X}$ & $\sqrt{ }$ & & & & & \\
\hline \multirow{2}{*}{ Heroin } & US & spike & & & & & $\sqrt{ }$ & \\
\hline & & sack & & & & $\sqrt{ }$ & & \\
\hline \multirow{3}{*}{ Cocaine } & US & cloud & $\sqrt{ }$ & & & & & \\
\hline & UK & coke & & & $\sqrt{ }$ & & & \\
\hline & & crack & & & & & $\sqrt{ }$ & \\
\hline Ketamine & $\begin{array}{l}\text { US and } \\
\text { UK }\end{array}$ & purple & $\sqrt{ }$ & & & & & \\
\hline
\end{tabular}

\section{NOTE:}

App. : Appearance

Eff. : Effects

Cons. : Constituent

Cont. : Container

Way : Way of consuming

Place : Place of origin 